\title{
cmaJOPEN
}

\section{Engagement of nurse practitioners in primary health care in northern British Columbia: a mixed-methods study}

\author{
Erin C. Wilson PhD NP(F), Robert Pammett MSc BSP, Farah McKenzie MScN NP(F), \\ Helen Bourque $\mathrm{MScN}$ NP(F)
}

Abstract

Background: Nurse practitioners (NPs) have been regulated primary care providers in British Columbia since 2005; however, many practices and contributions of NPs, especially those in northern or rural regions, remain unarticulated in primary health care. The objective of this study was to evaluate NP practices in the context of providing primary health care in northern BC.

Methods: This was a qualitative-dominant mixed-methods study. We recruited NP participants working in northern BC; recruitment and data collection occurred between April and June 2018. Participants completed the validated 28-item Primary Health Care Engagement (PHCE) Scale to assess their perceptions of their workplace with 8 attributes of primary health care (quality improvement, community participation, patient-centred care, accessibility, intersectoral team, interdisciplinary collaboration, continuity and population orientation). We also interviewed NPs about their everyday practice. Transcribed data from the interviews were analyzed interpretively.

Results: In total, 13 of 30 (43\%) eligible NPs participated in the survey and interview. The PHCE Scale results showed that all NPs perceived their workplaces to be highly engaged in patient-centred care, but none reported their workplaces as accessible. Interview data were organized into 5 headings which described how NPs see patients who are medically and socially complex, address inequities in access, practice collaboratively, address local service gaps and improve patient abilities to access care.

Interpretation: In interprofessional primary health care teams, NPs are key members and attend to both direct patient care and broader social conditions affecting health. Nurse practitioners can help accelerate advancements to deliver responsive community-based primary health care.

$\mathrm{P}$ rimary health care reforms in many countries include paying attention to increasing access to health care. One approach to improving access in Canada is integration of nurse practitioners (NPs) into primary care, particularly in rural settings, where NPs are more likely to work in the community rather than in a hospital. ${ }^{1}$ This study focuses on the practices of NPs working in northern British Columbia, where factors influencing integration of NP roles can include the combination of changing patterns in the family physician workforce, ${ }^{2}$ increasing patient medical and social complexity ${ }^{3,4}$ and uptake of the message by decisionmakers that "NPs increase access to care." ${ }^{5}$ Nurse practitioners have been regulated primary care providers in British Columbia since 2005.

Access to health care is dependent on interrelated dimensions of the health system and abilities of patients, ${ }^{6}$ and although evidence supports that NPs do increase access to care, ${ }^{7,8}$ few studies have evaluated how this is accomplished. ${ }^{6-10}$

As advanced practice nurses, NPs have competencies that extend beyond direct patient care to encompass proficiencies related to research, education and leadership. ${ }^{11}$ Therefore, NPs are poised to contribute to a shift toward delivery of comprehensive, interprofessional, community-based primary health care, ${ }^{12,13}$ and away from selective or niche models of primary care that may not address patient or community needs in a thorough manner., ${ }^{71}$ The message that NPs increase access is consistently offered as a rationale for NP role creation, ${ }^{15-17}$ but there may be more nuanced aspects of NP practice that can be explicated to support further successful integration of NP roles and strengthen the primary health care system.

The aim of this study was to evaluate how NPs are engaged in primary health care practices in the context of their work settings as salaried health authority employees who are part of interprofessional primary care teams in northern $\mathrm{BC}$ primary care clinics.

\section{Methods}

\section{Design}

The study was a qualitative-dominant mixed-methods study, ${ }^{18}$ using a survey and interviews. The study team included 3 members whose roles encompass research and clinical work

\section{Competing interests: None declared.}

This article has been peer reviewed.

Correspondence to: Erin Wilson, erin.wilson@unbc.ca

CMAJ Open 2021. DOI:10.9778/cmajo.20200075 
(E.C.W., R.P. and F.M.) and 1 member whose role includes decision-making (knowledge user) and clinical work (H.B.).

\section{Study sites and participants}

The Northern Health region in BC serves a population of about 300000 people over $617000 \mathrm{~km}^{2}$, an area the size of France. ${ }^{22}$ All NPs currently registered and employed as salaried health authority employees in primary care clinics in northern $\mathrm{BC}$ were eligible to participate. Participant recruitment was undertaken between Apr. 9 and June 22, 2018, via email; inclusion criteria included willingness to complete a survey and participate in a recorded interview.

\section{Data sources}

Participants completed the Primary Health Care Engagement (PHCE) Scale, a 28 -item validated scale ${ }^{19}$ to assess NP perception of workplace engagement in primary health care. The PHCE Scale was developed for use with rural nurses and attends to attributes of primary health care through 8 subscales measuring level of agreement about attributes of contemporary community-based primary health care, ${ }^{20}$ including quality improvement, community participation, patientcentred care, accessibility or availability, intersectoral team, interdisciplinary collaboration, continuity and population orientation. ${ }^{19}$ Responses for the PHCE Scale are scored based on a 5-point Likert scale that we recoded to "agree" (strongly agree or agree as the response) or "does not agree" (neutral, disagree or strongly disagree as the response). Higher levels of agreement reflect participants' perception of their workplace to be engaged with attributes of primary health care. Completion of the PHCE scale was followed by an interview with NPs about their experiences and descriptions of everyday practices and concluded with collection of sociodemographic information (Appendix 1, available at www.cmajopen.ca/ content/9/1/E288/suppl/DC1).

The interview guide was initially developed by E.C.W. The guide was based on a hermeneutic approach ${ }^{21}$ to elicit key features of care and experiences of NPs related to their everyday practices, to deepen understanding of the topic. Cognitive testing was completed within the study team (R.P., F.M. and H.B.).

\section{Data collection}

All data were collected between Apr. 9 and June 22, 2018, over the telephone or in person in single instances by 1 of 2 research assistants who underwent interview training with 1 of the authors (E.C.W.). The research assistants collected all data to protect confidentiality and anonymity of the participants, as many NPs in the region are known personally to the coauthors. Dual roles contributing to lack of anonymity can be common when conducting rural health research. ${ }^{23}$ Survey responses, sociodemographic data and interviews were completed verbally and collated by the research assistants.

The survey was administered first, followed by the interview and then collection of the sociodemographic data. The interviews were recorded and then professionally transcribed. The research assistants reviewed the transcripts for accuracy and redacted any key identifying data in the transcripts, such as names of towns or clinics, to help protect participant confidentiality. Participants were then assigned pseudonyms, and the redacted transcripts were given to the research team for analysis. Sociodemographic data were used to describe the sample but not linked to participant transcripts, as this too posed risks to confidentiality and anonymity of the participants.

\section{Data analysis}

Drawing on a hermeneutic approach, 3 members of the study team (E.C.W., R.P. and F.M.) completed independent reads of the transcripts and recorded interpretive memos. ${ }^{21}$ The team met twice in person to discuss interpretations. The first meeting was to discuss reflexively divergences in interpretations and what seemed familiar or strange in the data. ${ }^{21}$

In the second meeting, all members of the study team (E.C.W., R.P., F.M. and H.B.) held in-depth discussions reflecting how interpretations were supported by the data. While the knowledge user (H.B.), who uses research results to make decisions, ${ }^{24}$ participated in this meeting, the other members (E.C.W., R.P. and F.M.) made final decisions about the most fitting interpretations that could be articulated and would invite dialogue. ${ }^{21}$ Patterns noted and discussed during interpretation were given headings to aid in understanding where there was affinity within the data supporting interpretations.

The PHCE Scale ${ }^{19}$ data were analyzed descriptively. The purpose of including the PHCE Scale was to enhance description and illuminate differences in NP perceptions of how workplace structures and organization of care attended to primary health care attributes such as accessibility, patient-centred care, community participation and quality improvement. ${ }^{19}$

Integration of the interview and survey data occurred during analysis, to evaluate not only how NPs were engaged in primary health care practices, but also how they perceived their workplace to be engaged in delivering primary health care services, and how workplace engagement in primary health care may affect everyday practices of NPs.

\section{Ethics approval}

Ethics approval was obtained from the Research Ethics Board University of Northern British Columbia and Northern Health Research Review Committee. The knowledge user was not involved in primary analysis and did not have access to primary data.

\section{Results}

In total, 13 of 30 eligible NPs participated (43\%); 12 participants were interviewed by telephone and 1 in person. Interviews lasted between 30 and 60 minutes. Most participants were female, had completed graduate (NP) education within BC and were employed by Northern Health. Table 1 provides further demographic characteristics of participants.

\section{Primary Health Care Engagement Scale findings}

We used the PHCE Scale ${ }^{19}$ to assess the extent to which NPs perceive their workplace to be engaged in core attributes of primary health care (Figure 1). 
The results of the PHCE Scale show that all NP participants agreed that their workplace was engaged in patientcentred care, yet none agreed that their workplace offered

\begin{tabular}{|cc|}
\hline \multicolumn{2}{|l|}{ Table 1: Demographic characteristics of participants $(\boldsymbol{n}=\mathbf{1 3})$} \\
\hline Characteristic & No. (\%) of participants \\
\hline Years of experience as NP & $8(62)$ \\
\hline$<5$ & $5(38)$ \\
\hline$>5$ & \\
\hline Years of experience as RN & $5(38)$ \\
\hline$<5$ & $3(23)$ \\
\hline $5-10$ & $5(38)$ \\
\hline$>10$ & $2(15)$ \\
\hline Number of practice sites & $11(85)$ \\
\hline 1 & $10(77)$ \\
\hline$>1$ & $3(23)$ \\
\hline Focus of practice & $8(62)$ \\
\hline Primary care & $5(38)$ \\
\hline Primary care + specialty care \\
\hline Geographic location \\
\hline Urban (population $>10000)$ \\
\hline Rural (population $<10000)$ \\
\hline Note: NP = nurse practitioner, RN $=$ registered nurse. \\
\hline
\end{tabular}

flexible availability or accessibility to patients. The ways in which the workplaces of NPs attend to a population orientation, continuity of care or quality improvement in service delivery were endorsed by less than half of the participants, which may affect how and whether NPs are able to enact specific primary health care practices within the structure of the clinics supporting their role.

\section{Interview findings}

The interview findings are organized within 5 different headings that reflect interpretation of the data. Each heading highlights a facet of NP practice that attends to attributes of primary health care, including population orientation, accessibility, interdisciplinary collaboration and patient-centred care (Box 1).

\section{Attending to medical and social complexity}

Nurse practitioners described their patient population to be medically and socially complex. They considered impacts of homelessness, food insecurity and poverty on the treatment and management of patients they care for. Participants described patients at an individual level and at a practice or population level as being affected by social conditions that can perpetuate ill health (Box 1).

\section{Addressing inequities in access}

Nurse practitioners structured their practice to better accommodate patients who had previously encountered structural and cultural barriers to accessing care safely. They took

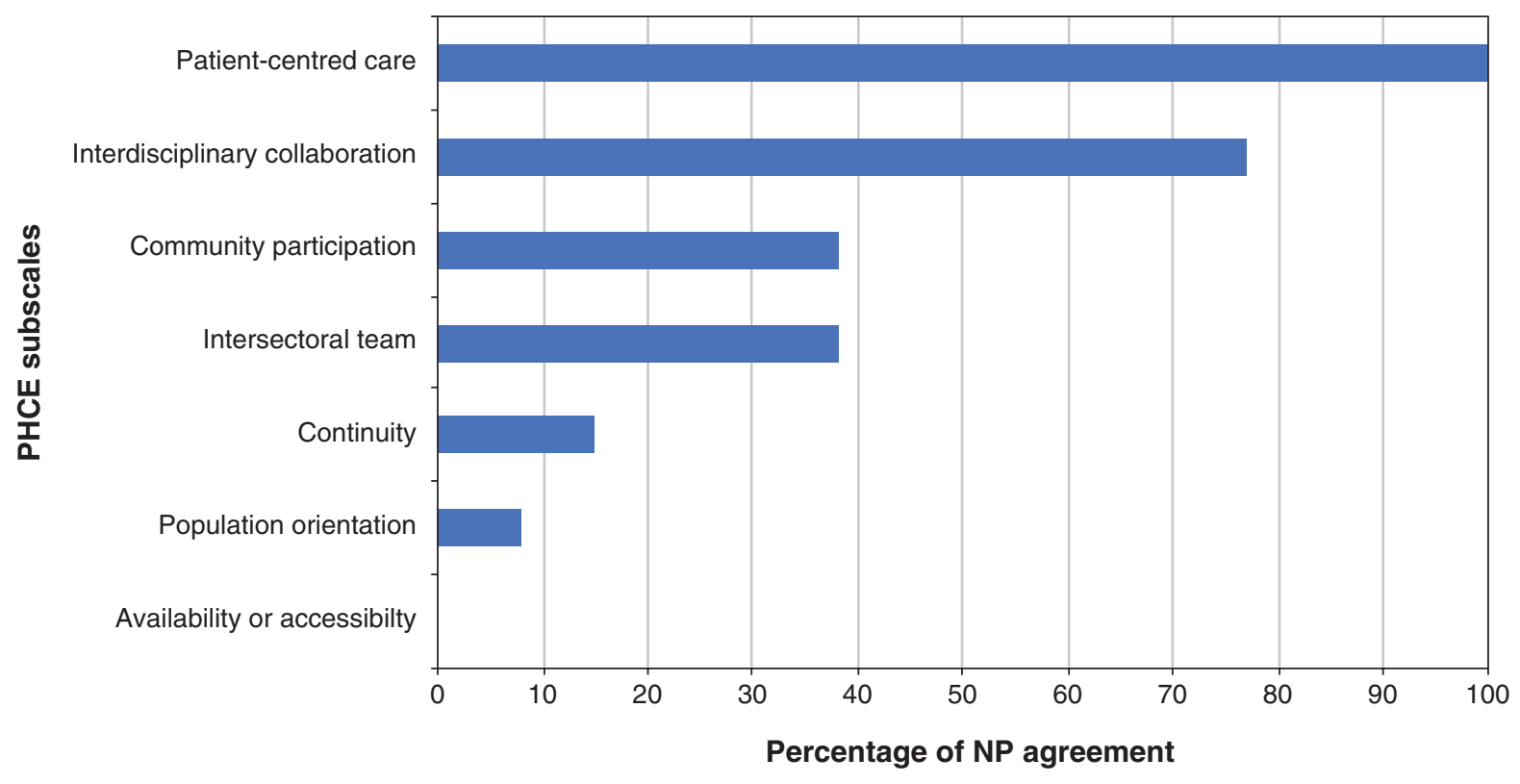

Figure 1: Percentage of nurse practitioners who agreed or strongly agreed that their workplace was engaged in attributes of primary health care as measured by subscales of the Primary Health Care Engagement Scale. The responses were scored based on a 5-point Likert scale, which we re-coded to "agree" (strongly agree or agree as the response) or "does not agree" (neutral, disagree or strongly disagree as the response). Note: NP = nurse practitioner, PHCE = Primary Health Care Engagement. 
Box 1: Examples of quotes reflecting participants' views on facets of nurse practitioner practice that attend to attributes of primary health care

\section{Attending to medical and social complexity}

- $\quad$ She [has] schizophrenia with psychotic features and poorly controlled diabetes and chronic pain. (NP1)

- $\quad$ [S]he lives with HIV, has significant cognitive impairment and addiction; she's homeless; she also has a seizure disorder. (NP3)

- I see lots of hungry people. (NP5)

- They're a vulnerable population and they've had a lot of poor experiences with the health care system because of that. (NP6)

- $\quad[$ T]ransportation is a huge problem for most people. (NP9)

\section{Addressing inequities in access}

- $\quad[W]$ e have same-day appointments in a clinic in a primary care setting. In the outreach clinics, we have nurse appointments that are available as walk-in. (NP2)

- Going to the ... clinic where people are very isolated, and I know I can save people a lot of money and hassle like to get to the nearest community which is strapped for doctors and provide decent primary care. (NP9)

- $\quad[S]$ o, the Aboriginal populations, I go right to their communities, and in some cases, I go right to their homes. (NP7)

- Doing a snowshoe led by one of the Elders, they [tell] stories ... so they get people out walking and learn about their history, and then follow it up with a [traditional foods] cooking class. (NP8)

\section{Practising collaboratively}

- I'll often be taking calls from nurses in other clinics and calls from those patients because l'm only there once a week ... and then also hallway chats with mental health colleagues who keep in touch with what's going on with those folks. We're managing as a team and then networking with other community providers, whether it's counsellors or teachers or [social services], Band Office staff, that sort of thing. (NP1)

- Lots of work with the nonprofits around homelessness ... lots of collaboration. (NP10)

\section{Addressing service gaps}

- I do quite a bit of women's health because historically our community only had male physicians. (NP1)

- I've also taken on the role, just because we don't have a public health nurse doing things like sex education for the school. (NP8)

- I do some outreach so I attend a clinic once a month on a First Nations reserve and once a week I attend a clinic ... at a homeless shelter ... and a clinic at a high-risk high school. (NP7)

\section{Improving patient abilities to access care}

- I just assume that every patient I see has experienced trauma in the past. (NP4)

- My goal is to develop a relationship with the person that's longitudinal ... when there's an increased medical need ... l'll be seen as trustworthy. (NP6)

- Looking at people's circumstances and why they might be having difficulty communicating their needs and ... really having compassion and empathy for where that might be coming from. (NP10)

- I hope that what I deliver continuously would be genuine interest and respect for the person in front of me, not just whatever their medical needs are. (NP6)

- I really try and let the patient decide what they want to do with their health care ... I really try not to just prescribe and tell them to take it. (NP4)

- When all of a sudden the trajectory of the course of your treatment is completely changing because the patient has taken ownership of their health. (NP7)

Note: NP = nurse practitioner.

initiative to practice outside traditional primary care clinic structures by taking on roles to engage in outreach and frequently travel not just outside their clinic but outside their community to deliver primary health care (Box 1).

\section{Practising collaboratively}

We asked NPs about interprofessional collaboration with an open-ended question. Their answers (Figure 2) illustrate that perception of "team" may not always be the formal grouping as defined by the health authority, and it may include members who are usually considered peripheral to delivery of primary care.

The concept of team for the NP participants extended beyond the clinic walls to include interagency or intersectoral collaboration. In practising interprofessional collaboration, NPs were considering the concept of team from the perspective of what services or resources patients require, rather than who can support the work of the NP (Box 1).

The NPs in this study inherently saw their role as part of team-based care, that interprofessional collaboration was beneficial to patients and that increased interaction with outside agencies or sectors could be helpful.

\section{Addressing service gaps}

Practice and organizational mechanisms and processes including health human resource skill mix influences integration of NPs into teams. Team composition varies by workplace, and this can affect how NPs enact their role. Nurse practitioners 


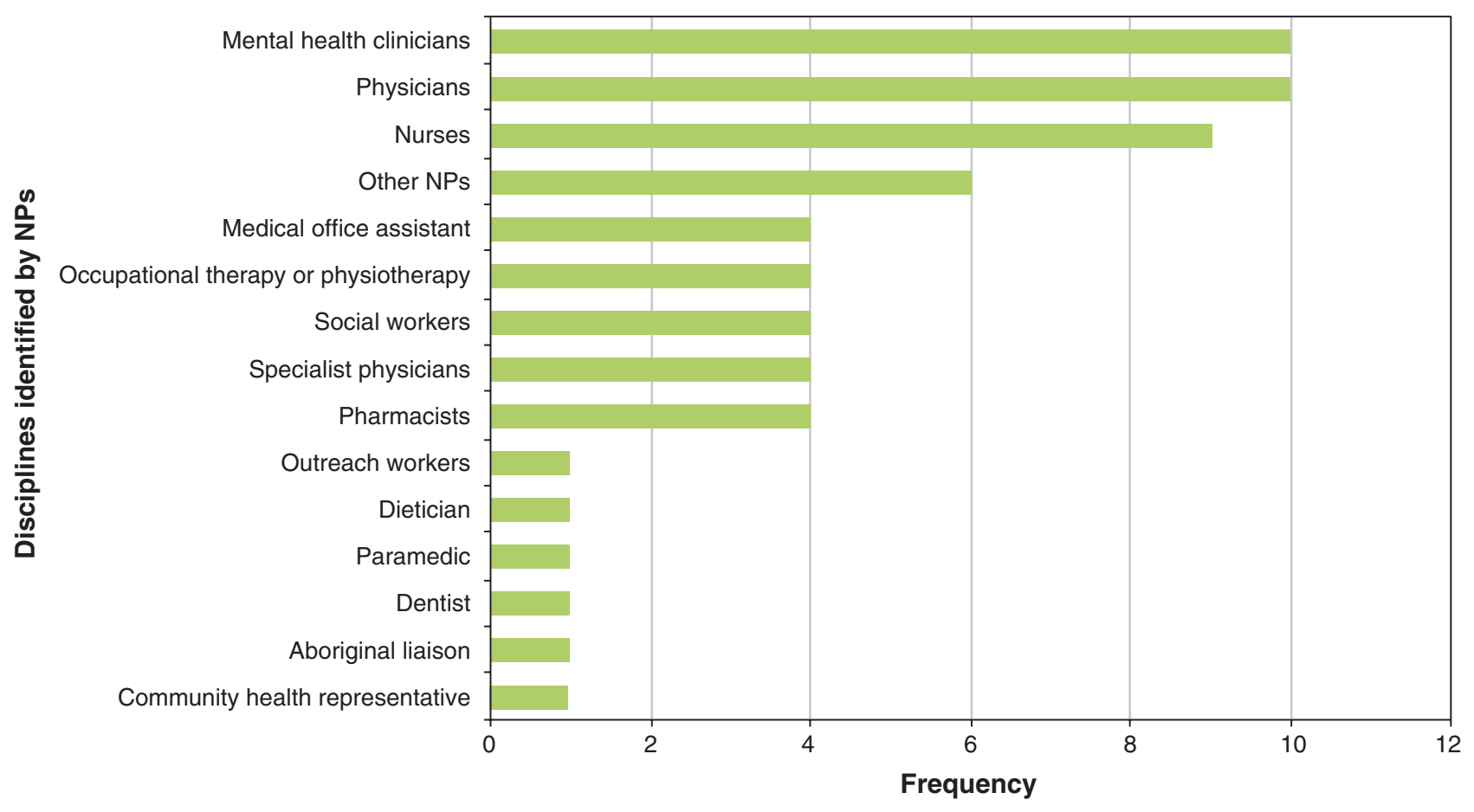

Figure 2: Frequency with which nurse practitioners identified a discipline in which they worked closely with other health care professionals. Note: NP = nurse practitioner.

described taking on roles that have not been fulfilled by existing programs or structures within their clinic workplace. As NPs recognized a gap in service, they adjusted their practice role and often moved their practice to where the patients were, rather than waiting for patients to attend the clinic that is their primary workplace setting (Box 1).

\section{Improving patient abilities to access care}

Many of the practices NPs engaged in to exemplify their role reflected efforts to reduce access barriers for patients. Nurse practitioners incorporated this approach not only into their practices that extended beyond direct patient care and outside the clinic walls, but also within individual patient encounters. Nurse practitioners sought to be accessible to patients through tailored relational approaches (Box 1).

\section{Integration}

The extent to which NPs perceived their workplace to be engaged in core attributes of primary health care was supported and confirmed by the interviews. The interviews yielded further insights towards understanding how primary health care attributes may be enacted at a practice level.

\section{Interpretation}

The findings of this study articulate how NPs working in the geographically vast and sparsely populated region of northern
$\mathrm{BC}$ engage in practices that promote primary health care, particularly in making linkages between patient health conditions and social conditions that affect health. The NPs in this study perceived that their workplace is not structured to attend to some attributes of primary health care, such as access, population orientation, continuity or intersectoral team. Despite these perceived constraints, NPs describe their autonomous practice in ways that attend to these primary health care attributes by drawing on their knowledge of patients, team composition and community context to shape their own role using approaches that could redress inequities for patients and promote primary health care.

Previous research has highlighted that NPs are committed to attending to the social determinants of health, ${ }^{14}$ and that NPs may prioritize social or economic issues ${ }^{25}$ over a biomedical focus. Although research has clearly shown the benefits of the NP role, for example, that NPs improve clinical outcomes and deliver quality care accompanied by high levels of patient satisfaction, ${ }^{26-29}$ and that NPs help reduce use of emergency departments ${ }^{30}$ and hospitals, ${ }^{31}$ it is necessary to describe the actual practices that contribute to these outcomes so that they can be understood and formally supported.

One aspect of NP practice that deserves further attention is how NPs are integrated as collaborative members of an interprofessional team. For example, Martin-Misener and colleagues $^{32}$ found that NPs working in nursing homes acted as a resource person for registered nurses, provided education to 
community groups and participated on committees, similar to NPs in our study. However, NPs in our study also described how they attempted to address gaps in service for the community. Although these activities may represent the ways in which NPs are moving primary care "upstream" 33,34 into the realm of primary health care, these practices could be more closely evaluated by health care planners and decision-makers, given the extent to which some of the activities (e.g., school visits) overlap with a registered nurse role. If NPs fill gaps in care that could be more readily provided by other members of an interprofessional team, this may obscure a need to further expand interprofessional teams and add to the diversity of disciplines to serve rural and northern communities.

Both within and beyond direct patient care encounters, NPs describe practices that can enhance approachability, acceptability, availability, affordability and appropriateness of care. ${ }^{6}$ The results of this study describe NP practices that are patient-centred and population-oriented. Through such approaches, NPs may be influencing patient abilities to access care, especially how patients are able to perceive, reach and engage in care. ${ }^{6}$ This enhances current discourse in describing the ways in which NPs can increase access and may help improve role integration within interprofessional teams.

Future research could include provider-level instruments such as the PHCE Scale to assess changes in how workplaces engage in primary health care over time. Further studies are required to assess how and whether patient-centred approaches that attend to the social determinants of health contribute to improvements in patient abilities to access care from an interprofessional team that includes NPs. Interpretive approaches can clarify interconnections between micro-level practices and practice or system-level outcomes; continued qualitative research is necessary to understand these connections.

\section{Limitations}

This research was conducted with a small sample and response rate of $43 \%$, describing practices occurring in a localized geographical context. Data were self-reported by participants, and NPs presented their perceptions of their own practice and the engagement of their workplace in primary health care. More work is needed to understand practices of NPs within interprofessional teams in Canada and elsewhere.

\section{Conclusion}

Nurse practitioners are advanced practice nurses who have the expertise to engage with and enact primary health care attributes through their everyday practices. Continued attention to promote NPs as key members of interprofessional primary health care teams will help support successful integration of NP roles and generate advancements in delivering responsive community-based primary health care.

\section{References}

1. MacLeod M, Stewart N, Kulig J, et al. Nurse Practitioner National Survey Fact Sheet. In: Nursing Practice in Rural and Remote Canada II. Prince George (BC): University of Northern British Columbial 2018. Available: www. unbc.ca/sites/default/files/sections/rural-nursing/en/rrniinpfinalfactsheetup dated20190131.pdf (accessed 2020 Sept. 28).
2. Snadden D, Kunzli MA. Working hard but working differently: a qualitative study of the impact of generational change on rural health care. CMAJ Open 2017;5:E710-6.

3. Carter N, Valaitis RK, Lam A, et al. Navigation delivery models and roles of navigators in primary care: a scoping literature review. BMC Health Serv Res 2018;18:96.

4. Katz A, Chateau D, Enns JE, et al. Association of the social determinants of health with quality of primary care. Ann Fam Med 2018;16:217-24.

5. Carter N, Lavis JN, MacDonald-Rencz S. Use of modified Delphi to plan knowledge translation for decision makers: an application in the field of advanced practice nursing. Policy Polit Nurs Pract 2014;15:93-101.

6. Levesque J-F, Harris MF, Russell G. Patient-centred access to health care: conceptualizing access at the interface of health systems and populations. Int 7 Equity Health 2013;12:18.

7. Grant J, Lines L, Darbyshire P, et al. How do nurse practitioners work in primary health care settings? A scoping review. Int 7 Nurs Stud 2017;75:51-7.

8. Martin-Misener R, Kilpatrick K, Donald F, et al. Nurse practitioner caseload in primary health care: scoping review. Int 7 Nurs Stud 2016;62:170-82.

9. Carter N, Sangster-Gormley E, Ploeg J, et al. An assessment of how nurse practitioners create access to primary care in Canadian residential long-term care settings. Nurs Leadersh (Tor Ont) 2016;29:45-63.

10. Haggerty J, Burge F, Lévesque J-F, et al. Operational definitions of attributes of primary health care: consensus among Canadian experts. Ann Fam Med 2007;5:336-44.

11. Advanced practice nursing: a Pan-Canadian Framework. Ottawa: Canadian Nurses Association; 2019.

12. Community-based Primary Health Care. Ottawa: Canadian Institutes of Health Research; 2017. Available: https://cihr-irsc.gc.ca/e/43626.html (accessed 2020 Mar. 5).

13. Primary health Care. Geneva: World Health Organization; 2019. Available: www.who.int/health-topics/primary-health-care\#tab=tab_1 (accessed 2020 Mar. 5).

14. Housden L, Wong ST, Browne AJ, et al. Complexities of introducing group medical visits with nurse practitioners in British Columbia. Policy Polit Nurs Pract 2016;17:198-207.

15. Ministry of Health. Creating new opportunities for nurse practitioners as part of team-based care system [news release]. Victoria: Government of British Columbia; 2018 May 23. Available: https://news.gov.bc.ca/releases/ 2018HLTH0034-000995 (accessed 2019 Aug. 11).

16. Main page. Burnaby (BC): Nurses and Nurse Practitioners of British Columbia. Available: www.nnpbc.com/ (accessed 2019 Aug. 11).

17. Increase access to care by fully utilizing NPs. Toronto: Registered Nurses' Association of Ontario; 2019. Available: https://rnao.ca/sites/rnao-ca/files/Increase access_to_care_by_fully_utilizing_NPs_QPD_2019_Final_Public.pdf found (accessed 2019 Aug. 11).

18. Johnson RB, Onwuegbuzie AJ, Turner LA. Toward a definition of mixed methods research. 7 Mixed Methods Res 2007;1:112-33.

19. Kosteniuk JG, Stewart NJ, Karunanayake CP, et al. Exploratory factor analysis and reliability of the Primary Health Care Engagement (PHCE) Scale in rural and remote nurses: findings from a national survey. Prim Health Care Res Dev 2017;18:608-22.

20. Kosteniuk JG, Wilson EC, Penz KL, et al. Development and psychometric evaluation of the Primary Health Care Engagement (PHCE) Scale: a pilot survey of rural and remote nurses. Prim Health Care Res Dev 2016;17:72-86.

21. Moules NJ, McCaffrey G, Field JC, et al. Conducting hermeneutic research: from philosopby to practice. Peter Lang, International Academic Publishers; 2015:1-214.

22. Quick facts. Prince George: Northern Health. Available: www.northernhealth. ca/about-us/quick-facts (accessed 2020 Oct. 13).

23. Heslop C, Burns S, Lobo R. Managing qualitative research as insiderresearch in small rural communities. Rural Remote Health 2018;18:4576.

24. Glossary of funding-related terms. Ottawa: Canadian Institutes of Health Research; modified 2020 Oct. 19. Available: https://cihr-irsc.gc.ca/e/34190. html\#k (accessed 2020 Sept. 29).

25. Heale R, James S, Wenghofer E, et al. Nurse practitioner's perceptions of the impact of the nurse practitioner-led clinic model on the quality of care of complex patients. Prim Health Care Res Dev 2018;19:553-60.

26. Beaulieu MD, Haggerty J, Tousignant $\mathrm{P}$, et al. Characteristics of primary care practices associated with high quality of care. CMAf 2013;185:E590-6.

27. Donald F, Martin-Misener R, Carter N, et al. A systematic review of the effectiveness of advanced practice nurses in long-term care. 7 Adv Nurs 2013;69:2148-61.

28. Swan M, Ferguson S, Chang A, et al. Quality of primary care by advanced practice nurses: a systematic review. Int $\mathcal{7}$ Qual Health Care 2015;27:396-404.

29. Tsiachristas A, Wallenburg I, Bond CM, et al.; MUNROS team. Costs and effects of new professional roles: evidence from a literature review. Health Policy 2015;119:1176-87.

30. Roots A, MacDonald M. Outcomes associated with nurse practitioners in collaborative practice with general practitioners in rural settings in Canada: a mixed methods study. Hum Resour Health 2014;12:69.

31. Godleski L, Cervone D, Vogel D, et al. Home telemental health implementation and outcomes using electronic messaging. 7 Telemed Telecare 2012;18:17-9. 
32. Martin-Misener R, Donald F, Wickson-Griffiths A, et al. A mixed methods study of the work patterns of full-time nurse practitioners in nursing homes. 7 Clin Nurs 2015;24:1327-37.

33. Butterfield PG. Thinking upstream: nurturing a conceptual understanding of the societal context of health behavior. ANS Adv Nurs Sci 1990;12:1-8.

34. SmithBattle L. Diekemper M, Leander S. Moving upstream: becoming a public health nurse, part 2. Public Health Nurs 2004;21:95-102.

Affiliations: School of Nursing (Wilson), University of Northern British Columbia; Northern Health (Wilson, Pammett, Bourque), Prince George, BC; Faculty of Pharmaceutical Sciences (Pammett), University of British Columbia, Vancouver, BC; BC Cancer Centre for the North (McKenzie), Prince George, BC

Contributors: Erin Wilson conceptualized and designed the study, contributed substantially to the acquisition of data, led the analysis and interpretation and drafted the article. Robert Pammett and Farah McKenzie contributed substantially to the design, analysis and interpretation of the study and revised the article for important intellectual content. Helen Bourque contributed to the interpretation of the study and revised the article for important intellectual content. All authors gave final approval of the version to be published and agreed to be accountable for all aspects of the work.
Data sharing: Findings of this mixed-methods study are not available for use by other researchers.

Funding: Funding support was received from a Provincial Health Services Authority-Northern Health-University of Northern British Columbia Seed Grant.

Content licence: This is an Open Access article distributed in accordance with the terms of the Creative Commons Attribution (CC BYNCND 4.0) licence, which permits use, distribution and reproduction in any medium, provided that the original publication is properly cited, the use is noncommercial (i.e., research or educational use), and no modifications or adaptations are made. See: https://creativecommons.org/ licenses/by-nc-nd/4.0/

Acknowledgements: The authors thank Andrew Schulz, research assistant, for data collection and project management. The authors also thank the nurse practitioners who participated in the study.

Supplemental information: For reviewer comments and the original submission of this manuscript, please see www.cmajopen.ca/content/9/1/ E288/suppl/DC1. 